(

\title{
An Estimation of Actual Recycling and Final Disposal Rates of Municipal Solid Waste by
}

\author{
Material Flow Analysis in Korea
}

Jung-Keun Oh ${ }^{1}$, Ji-Yeon Kim ${ }^{1}$, Yoon-A Cho ${ }^{1}$, Ki-Heon Kim ${ }^{1}$, Gil-Jong Oh ${ }^{1, *}$

${ }^{1}$ Environmental Resources Research Department, National Institute of Environmental Research, Hwangyeong-ro 42, Seo-gu, Incheon 404-708, Republic of Korea

*Correspondence: giljong@gmail.com

\section{Abstract}

The recycling, incineration, and final disposal rate of municipal solid waste (MSW) are calculated based on the total amount of waste input to each facility in many countries. These statistic data have serious limitation in setting the national goal and policy for effective waste management because it is not considering the amount of foreign objectives in the process of each life-cycle stage. This case study is to estimate the actual rates of recycling, incineration, and final disposal by material flow analysis (MFA) after the collection of MSW in Korea. The actual rates of recycling, incineration and final disposal for MSW in 2016 were $49.9 \%, 32.9 \%$ and $23.1 \%$ respectively, indicating that the recycling rate was lower by $10.1 \%$, while the incineration and final disposal rates were raised by $7.6 \%$ and $8.4 \%$ respectively, compared with the statistics for current MSW. In addition, the changed actual rates of recycling, incineration treatment, and final landfill, and variation of waste treatment charge according to treated amounts per treatment method was analyzed. This results of this study will contribute to establish national level of plan on effective waste management. 
24 Keywords: actual recycling rate; material flow analysis; municipal solid waste; waste treatment

25 charge

\section{Introduction}

In South Korea, the Framework Act on Resource Circulation has been enforced since January, 2018. According to the article 11 and article 12 of this Act, the minister of Ministry of Environment should establish in every 10 years for the enforcement the Master Plan for Resource Circulation

31 presenting mid to long-term policy goals such as the efficient use of resources, the prevention of 32 waste generation, and the promotion of use of recycled resources, etc. Mayors of Seoul, metropolitan city, special self-governing city, and governors of provinces should establish the

34 yearly enforcement of the Master Plans including the investment plans to convert the area under jurisdiction to the resource circulation community; and obtain an approval from the minister of Ministry of Environment. Also, a mayor, a county governor, and a district head should establish the yearly execution plans of the enforcement plans for city and province by considering the circumstances of the areas under jurisdiction and submit them to mayor and province governor.

39 Based on the article 14 of this Act, the minister of Ministry of Environment should set mid to longterm target values per stage for final disposal rate, circulated use (actual recycling) rate, and energy recovery rate, and promote measures for their accomplishment. incineration rate, and final disposal rate are calculated as the ratio of the input amount to sorting 44 facilities (material recycling facility, MRF) for separate discharge as recyclable items, incineration facilities, and landfill sites, to the total collected amount of MSW. Namely, since only the input 
47 amounts of foreign objects (referring to the sorting residual waste generated from the process of

48 screening and recycling), those rates cannot be utilized directly for setting the above targets.

49 To establish the installation and operation plan for MSW treatment facilities, the input amounts

50 of wastes into the treatment facility should be known based on the material flow. In this study,

51 actual recycling rate, incineration rate, and final disposal rate were calculated through the MFA

52 that considered the generation and treatment of foreign objects and incineration residue from the

53 generation to the final disposal of wastes. And when treatment methods of MSW through direct

54 landfill were changed, changes in actual recycling rate and final disposal rate were analyzed and

55 evaluated as well as variations of the waste disposal charge which was started in January 1, 2018

56 by Framework Act on resource circulation. The results of this study will be used as valuable

57 information for the establishment by the Ministry of Environment and local governments of the

58 basic plans for resource circulation as well as corresponding enforcement and execution plans, and

59 for the preparation of improvement plans for waste statistics, etc.

60

61 2. Methodology

62 The cases of MFA on MSW in Japan and Germany were surveyed for reference. To analyze the

63 material flow according to actual situations from collection to intermediate treatment and final

64 disposal of MSW, the MSW was classified according to the classification of wastes separately

65 collected to calculate the material balance.

66 Generated amounts of MSW and treated amounts per treatment method have been used as basic

67 data from 'Nationwide Status of Waste Generation and Treatment in 2016' [1] as the latest MSW

68 statistics at the current point. Distribution coefficients to calculate the input amounts to the sorting

69 facility for recycled items, the manufacturing facility for Solid Refuse Fuel (SRF) and the 
70 treatment facility for food wastes, along with the generated amounts of foreign objects and

71 incinerated materials as well as foreign objects treatment methods were determined when the

72 personnel in charge of waste tasks in National Institute of Environmental Research, Korea

73 Environment Corporation, Korea Resource Circulation Service Agency gathered, discussed

74 several times and listened to an opinion on the results of the responsible person in the related

75 department of the Ministry of Environment, based on 2016 evaluation data of Korea Environment

76 Corporation on local governments' operation status for waste treatment facility, inside data of the

77 Ministry of Environment and the Korea Environment Corporation, survey data of the Korea

78 Resource Circulation Service Agency, and statistics of Statistics Korea, etc.

\section{Study results and Discussion}

3.1. Cases of MFA for MSW

\subsubsection{MFA for MSW in Japan}

83 Material flow of waste discharge and treatment in 2016 for MSW in Japan (corresponding to

84 MSW in Korea and MSW at business sites) is as shown in Appendix A (Fig. A1). Waste recycling

85 amount of Japan is 6.52 million tonnes based on the sum of 1.96 million tonnes for direct recycling

86 amount collected by local governments immediately followed by direct supply to recycling

87 businesses and 4.56 million tonnes for the amount sorted and recovered by intermediate treatment

88 facilities such as sorting facility for recycled items, crushing/sorting facilities, etc. for large size

89 wastes, corresponding to $15.9 \%$ of total waste treatment amount. In addition, the amount of waste

90 paper, steel scrap, etc. jointly collected by residents for direct sales to recycling businesses is 0.227

91 million tonnes. Total recycled amount based on the sum of all of these is 8.79 million tonnes,

92 corresponding to $20.4 \%$ compared with total discharged amount, or $21.4 \%$ compared with total 
93 treated amount.

\subsubsection{MFA for MSW in Germany}

96 As shown in Appendix A (Fig. A2), the input amount by treatment facilities in Germany in 2015

97 was 5.104 million tonnes among the collected amount of urban wastes (corresponding to MSW in

98 Korea and MSW at business sites) of 51.625 million tonnes, while the input amounts by material 99 recycling facilities and energy recovery facilities were 34.453 million tonnes (66.7\%) and 12.068 100 million tonnes (23.4\%) respectively. According to the Appendix A (Fig. A3), the recycled wastes 101 collected for material recycling are input to sorting facilities, $27 \%$ of which is removed first as 102 foreign objects, and 4\% of which is removed again as foreign objects in additional sorting process 103 to meet the conditions for subsequent input to final recycling facilities. Consequently, the amount 104 used as a raw material in the final manufacturing facilities for a recycling product is $36 \%$ of urban 105 waste generation.

106

107 3.2. MFA for MSW in Korea

108 3.2.1. Data used for MFA of MSW

109 As it can be seen in the cases of Japan and Germany mentioned in Section 1, the two countries 110 are assessing the recycling rate of MSW by the amount provided to recycling businesses as the 111 reference after the removal of foreign objects at sorting facilities rather than assessing the input 112 amount by sorting facilities or recycling facilities.

113 In the statistical data of MSW in Korea, wastes generated in households are classified as MSW, 114 and the wastes with the same appearance as that of MSW among wastes generated at business sites 115 are classified as MSW at business site. Both types are being called MSW. In this thesis, however, 
116 wastes for daily life will be called MSW by using a conventional terminology. Therefore, the MSW

117 in this thesis hereafter would mean the sum of MSW generated in households and MSW at business

118 sites. While 'Nationwide Status of Waste Generation and Treatment in 2016' is prepared based on

119 the daily waste generation, the value converted to annual generation by multiplying the daily

120 generation by 365 was used to analyze the material flow based on annual generation. As a reference,

121 the sum of the amounts of MSW collected and input to treatment facilities is assumed to be the

122 MSW generation in the current waste statistics. Since the area of MSW management zone in Korea

123 is $98,317.04 \mathrm{~km}^{2}$ and the population residing in this zone is $53,112,059$ people corresponding to

$12499.9 \%$ of the population in South Korea [2], the difference between generated amount and

125 collected amount of MSW is insignificant so that the above assumption does not produce any

126 problem. Also, this statistics classifies the generated amount and the treated amount of MSW into

1273 types for preparation, including mixed discharge according to the volume-rate waste disposal

128 system: discharge by designated plastic bag, separated discharge of recyclable resources, and 129 separated discharge of food wastes. Therefore, this study also followed the above classification

130 method. However, waste types were abbreviated as wastes in designated plastic bag, recyclable

131 resources, and food wastes. Status of generation and treatment of MSW in Korea is as shown in 132 Appendix B.

133 Korean government has never analyzed and disclosed material flow for the generation and 134 treatment of MSW, and is lack of base data that can utilize material balance per treatment process 135 of the same wastes. Thus, while disclosed data was used first when material balance of the 136 treatment process was calculated, the internal data of related institutions was used such as Ministry 137 of Environment, Korea Environment Corporation, Korea Resource Circulation Service Agency, 138 etc. when no disclosed data was available. Setting grounds for data and distribution coefficients, 
139

140

141

142

143

144

145

146

147

148

149

150

151

152

153

154

155

156

157

158

159

160

161

etc. used for MFA are as follows.

1) For MSW generation, generation per waste type, and input amount per type of waste treatment facility, the statistical data of 'Nationwide Status of Waste Generation and Treatment in $2016^{\prime}[1]$ was used.

2) Recyclable resources generated at apartments are separately discharged per item, and treated mostly in consignment as residents sign a sales contract with private recycling businesses. Recyclable resources produced in single-unit housing (referring to housings including studio other than apartment) tend to be discharged all at once rather than being discharged separately. They are collected by local governments, sorted per item by public sorting facilities and supplied to private recycling businesses. For the recyclable resources generated in apartments, separated discharge bins per recycling item are installed and managed by apartment security personnel for paid sales so that mingling rates of foreign objects are lower than the discharge from single-unit housings. Therefore, material flow was analyzed by classifying discharged amounts of recyclable resources generated in apartments and single-unit housings. With an assumption that the amounts of recyclable resources generated in apartments and single-unit housings were proportional to the residing population, they were distributed to be $53.06 \%$ and $46.94 \%$ respectively, according to the ratio of the number of residents by using 'statistical data for household members per type of residence in 2016 [3] housing census by the Statistics Korea.

3) Ratios for the sorted items generated in apartments and recovered by sorting facilities for recyclable resources and the removed foreign objects were selected to be $83.6 \%$ and $16.4 \%$ respectively, by referring to the input amounts of recyclable resources by recycling businesses where glass bottles, metals, synthetic resins are input per separate item (including reuse items) for sorting among the internal data of Korea Resource Circulation Service Agency [4]. Ratios for the sorted items generated in 
162 single-unit housings and recovered from the sorting facilities for recyclable resources and the removed foreign

163 objects were set to be $63.4 \%$ and $36.6 \%$ respectively, based on the generation rate of foreign objects

164 by recyclable resources sorting facilities (MRF) in 2016 operation status data for public MSW

165 treatment facilities [5].

166 4) According to the statistical data on solid fuel of the Korea Environment Corporation [6], the 167 amount of waste synthetic resin targeting the expanded producer responsibility system (EPR) was 168 0.296 million tonnes which was used as raw material for SRF manufacturing in 2016. Hence, this 169 amount was considered as the input amount of waste plastic film by SRF manufacturing facilities 170 after sorting from recyclable resources. And, the amount of sorted waste plastic film per housing 171 type was calculated by dividing this amount by the ratio for the total amount of sorted items of 172 recyclable resources from apartments and single-unit housings. In this statistics, based on the fact 173 that 0.296 million tonnes of waste synthetic resin was input to the SRF manufacturing facilities, 174 the SRF production yield of the same waste plastic film and the generation rate of foreign objects 175 was set to be $95.6 \%$ and $4.4 \%$ respectively.

176 5) The amount of sorted items for the material recycling of recyclable resources was determined 177 to be the value where the amount of waste plastic film for the EPR above was subtracted from the 178 amount of sorted items from apartments and single-unit housings.

179 6) Generation rate of the incineration residue to the input amount of MSW to incineration 180 facilities was set to be $19.0 \%$ as the generation rate of incineration residue from stoker-type MSW 181 incinerators according to 2016 operation status for public MSW incineration facilities [5]. As a 182 reference, 109 plants among 166 plants of MSW incineration facility as of the end of 2016 are 183 stoker type, and the amount of treatment by this type of incineration facilities was $90 \%$ of total 184 incinerated MSW (4.751 million tonnes) in 2016. 
7) For the recycled amount per recycling method of separately collected food wastes, the internal data of the Ministry of Environment [7] was used. According to the same data, the daily recycled amount in 2016 was 13,465 tonnes/day including small-scale restaurants and mass-discharging businesses, where the daily input amounts per recycling method were 6,141 tonnes (45.6\%) for feed conversion, 4,139 tonnes (30.7\%) for compost conversion, 1,381 tonnes $(10.3 \%)$ for biogas conversion, and 1,804 tonnes (13.4\%) for other recycling. Meanwhile, according to 'Nationwide Status of Waste Generation and Treatment in 2016', daily generation of food wastes was 14,388.7 tonnes, recycling 13,936.3 tonnes, incineration 316.9 tonnes, and landfill 135.5 tonnes, where this recycled amount was more than the recycled amount in the internal data of the Ministry of Environment by 471 tonnes. Therefore, the input amount for treatment facilities per recycling method was determined by multiplying the recycled amount of food wastes in 'Nationwide Status of Waste Generation and Treatment in 2016 ' by the composition ratio per recycling method in the internal data of the Ministry of Environment. This is because the above waste statistics only contain data on the total recycled amount of food waste, and there is no data on recycled amounts classified by recycling methods. The values of the above statistics were used directly for the amounts of incineration treatment and landfill of food wastes.

8) According to the internal data of the Environment Corporation [8], 0.556 million tonnes of wastes in designated plastic bag among MSW in 2016 were input to solid fuel manufacturing facilities to produce 0.305 million tonnes of SRF. Therefore, the production yield was $54.9 \%$. Meanwhile, according to the evaluation results by the Environment Corporation of 2016 operation records for 12 facilities of solid fuel manufacturing facilities in local governments [5], production yield for SRF was $47.8 \%$, generation rate of foreign objects $35.4 \%$, and process loss rate $16.8 \%$. Such differences are considered to have occurred because the manufacturing facilities for solid fuel with a small 
208

209

210

211

212

213

214

215

216

217

218

219

220

221

222

223

224

225

226

227

228

229

230

number of operating days were excluded from the evaluation facility. The reason is that Daegu and Daejeon metropolitan cities have a large scale manufacturing facilities for solid fuel with the production of fluff SRF so that the production yields are high. Thus, the values of data from the Ministry of Environment were used directly for the input amount of wastes to SRF manufacturing facilities and the production amount of SRF in 2016. The amount (251 tonnes) subtracted the manufactured amount of SRF from the input amount was considered as foreign objects and a process loss, and these ratios were determined to be $68: 32$ by assuming $35.4 \%: 16.8 \%$ as in the evaluation data for operation records of Korea Environment Corporation. Meanwhile, material balances, when solid fuel was produced from directly land-filled wastes in designated plastic bag, were determined to be $54.9 \%$ for the production yield, $30.7 \%$ for the generation rate of foreign objects, and $14.4 \%$ for the process loss rate by referring to the two data above.

9) Production yield and generation rate of foreign objects per recycling method of food wastes are from 2016 data for operation status of public MSW treatment facilities. The ratios for the produced amount of recycling product per recycling method and the generation amount of foreign objects in treatment facilities for food wastes ( 79 facilities) were set to be $14.0 \%$ and $4.4 \%$ for feed conversion, $13.5 \%$ and $7.9 \%$ for compost conversion, $7.1 \%$ and $16.7 \%$ for bio gas conversion, $32.1 \%$ and $5.6 \%$ for other cycling respectively. Production yield for bio gas conversion was set as the ratio of weight calculated by multiplying the produced volume of biogas by the density of methane gas to the input amount assuming that total amount of bio gas was methane gas. Generation rate of foreign objects was set as the ratio of the sum of the amount of foreign objects removed from pre-treatment facility of anaerobic digestion facilities and the amount of solid residues produced after anaerobic digestion to the input amount of food waste.

10) The ratios per treatment method of foreign objects generated by sorting facilities for 
231 recyclable resources were determined to be $83 \%$ for incineration treatment and $17 \%$ for landfill

232 treatment according to the ratio of the sum of the amount of incineration and the amount of landfill

233 by the public sorting facilities for recyclable resources (175 facilities) in 2016 data on operation

234 status of public MSW treatment facilities. Although these values are ratios for the treatment

235 method of foreign objects in sorting facilities operated by local governments, these ratios were

236 also applied to the treatment of foreign objects generated in sorting of recyclable resources

237 collected from apartments since there was no data available on the treatment methods of foreign

238 objects by sorting facilities of private recycling businesses.

239 11) Currently, since foreign objects of manufacturing facilities for SRF are landfilled and foreign

240 objects of recycling facilities for food wastes are incinerated, these treatment methods were applied

241 directly for foreign objects in the same facilities.

242

243 3.2.2. Results of MFA for $M S W$

244 Currently, basic local governments of Korea classify MSW into recyclable resources, designated

245 plastic bag wastes, and food wastes for collection and treatment. Therefore, material flow diagram

246 was prepared by classifying MSW in this way and calculating material balance according to the

247 ground described above, and the results are as shown in Figure 1. 


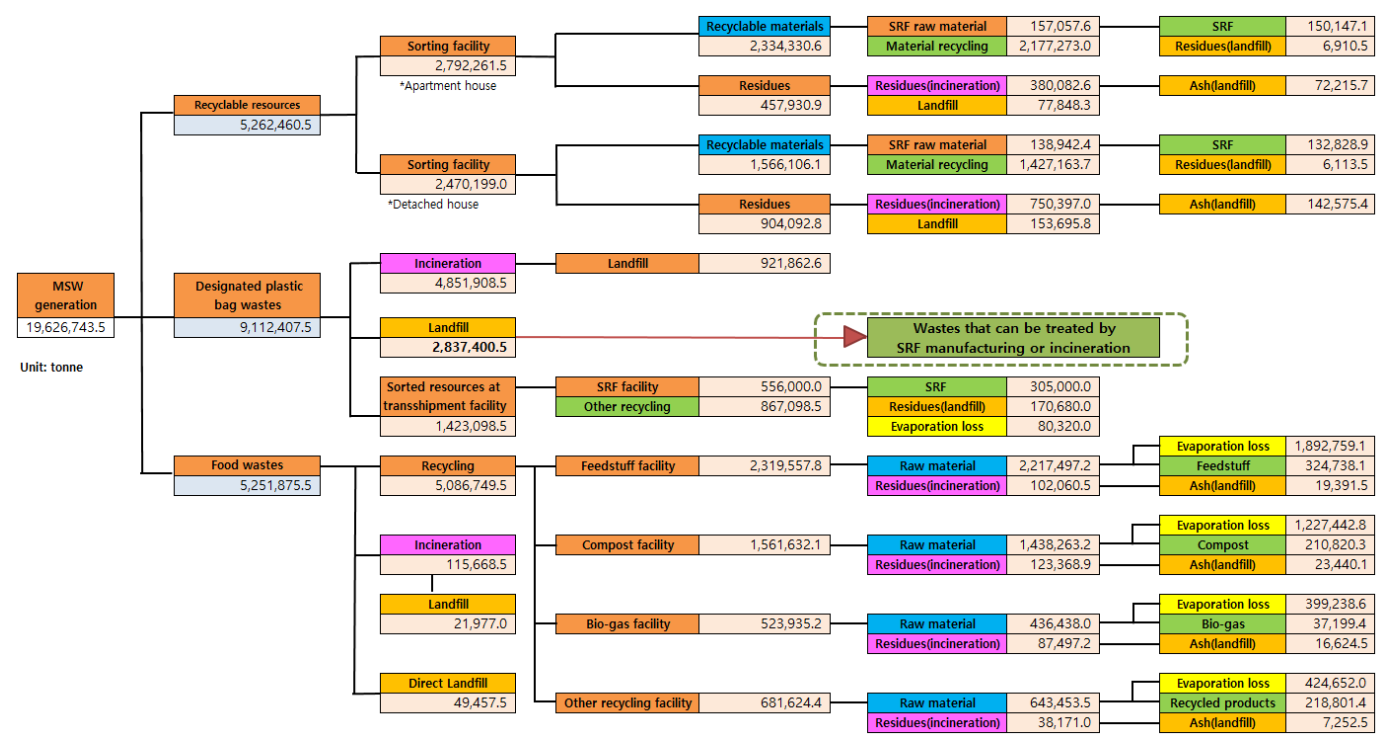

250 Figure 1. Material flow of MSW (2016).

251

In the material flow of Figure 1, the ratios per treatment method were summarized for easy

253 understanding and shown in Figure 2. As shown in Figure 2, the generation of MSW in 2016 was

25419.627 million tonnes. The input amount to sorting facilities and recycling facilities (recycling

255 facility for food wastes, manufacturing facility for SRF) was 11.772 million tonnes, corresponding

256 to $60.0 \%$ of the generation amount of MSW. In 'Nationwide Status of Waste Generation and

257 Treatment in 2016 ' by the Ministry of Environment, this value is specified as the recycling rate.

258 The total amount of sorted items recovered by the input of recyclable resources to sorting processes

259 and the input amount of food wastes to recycling process after the input to recycling facilities

260 followed by the removal of foreign objects in pre-treatment process was 10.059 million tonnes,

261 corresponding to $51.3 \%$ of MSW generation. Waste plastic film among sorted items recovered

262 from recyclable resources is used for manufacturing SRF. The recycling rate is $49.9 \%$ if the amount

263 removed as foreign objects (referring to unsuitable material for SRF) during such process is

264 excluded. In actual recycling businesses, foreign objects in the sorted resources are removed again 
265 to meet the delivery requirements of final recycling companies. For example, glass bottles sorted 266 per color are crushed and processed for shredded glasses (it is called cullet.) after the removal of 267 foreign objects such as glass bottles of different colors, ceramic wares, plastics, metals, etc. to meet 268 the requirements of bottle-making companies. Metal cans are compressed to remove residual water 269 or gas, etc. after the removal of foreign objects such as plastics, soil, and sand, etc. through screen 270 sorting, followed by crushing and sorting to meet the requirements of steel-making companies. 271 After sorting into PET, PE, PP, etc., plastics are sorted again and crushed to remove foreign objects 272 through sorting by difference in specific gravity, dehydrated \& dried, followed by processing into 273 pellet or flake for delivery to the manufacturers of plastic products, etc. After the removal of 274 foreign objects, waste papers are classified into newspaper, printing paper, corrugated board, etc. 275 and compressed for delivery to paper companies. Paper is manufactured by removing foreign 276 objects again in a dissociation process. In this way, the sorted items classified per item after the 277 removal of foreign objects from recyclable resources are used as a raw material for products after 278 undergoing another sorting process or additional removal of foreign objects prior to delivery to 279 manufacturing facilities for final recycling. However, in this study, data on this was not secured so 280 that the amount supplied to recycling businesses after the removal of foreign objects and the 281 classification by sorting facilities was considered as the actual amount of recycling. However, since 282 related data by the Ministry of Environment is available on the amount of foreign objects removed 283 additionally while SRF is manufactured by waste plastic film among sorted items, actual recycled 284 amount was calculated by excluding this amount. Since food wastes have a high water content of 285 about $80 \%$ and a large amount of the water is evaporated in the recycling process but also the water 286 content of final recycling products (feed, compost, etc.) is not constant and there is no method to 287 determine how to handle water in calculation of recycling rates, the amount excluding foreign 
288

289

290

291

292

293

294

295

296

297

298

299

300

301

302

303

304

305

306

307

308

309

310

objects was considered as the recycled amount. As shown in Figure 1, material balance for the recycling process of food wastes is 0.792 million tonnes for the production of recycling products, 0.351 million tonnes for the generation of foreign objects, and 3.944 million tonnes for the loss amount due to water evaporation, etc. Composition ratios compared with the input amount of food wastes to recycling processes are $15.1 \%, 77.5 \%$, and $6.9 \%$ respectively, where the loss rate due to water evaporation, etc. is large.

As it can be seen in Figure 2, the input amount to incineration facilities immediately after the collection of MSW in 2016 was 4.968 million tonnes, which is $25.3 \%$ of the generation of MSW. However, since the incinerated amount of 1.474 million tonnes of foreign objects was added, the actual incinerated amount was 6.441 million tonnes, which is $32.8 \%$ of the generation of MSW. Also, the amount of direct landfill was 2.887 million tonnes accounting for $14.7 \%$ of the generation of MSW. However, since the landfilled amount of foreign objects and incinerated material of 1.647 million tonnes (In Figure 2, the figure was rounded up to make the sum of the landfilled amount to be 1.648 million tonnes which was larger than actual value) was added, the actual final disposed amount was 4.534 million tonnes, which is $23.1 \%$ of the generation of MSW.

According to No. 4 of Clause 1 of Article 7 in the enforcement decree for Waste Management Law, wastes generated in the process of recycling or intermediate=treatment are counted as newly generated waste and impose duty to report to administrative office as a waste generator. According to the same regulation, foreign objects and incineration residue generated in MSW sorting \& treatment facilities (including recycling facilities) correspond to business site wastes. As shown in Figure 2, the amount removed as foreign objects from sorting facilities and recycling facilities of MSW (including SRF manufacturing facilities) is 1.897 million tonnes, which is $9.7 \%$ of the generation of MSW while the amount of incineration residue is 1.224 million tonnes, which is 
$3116.2 \%$ of the generation of MSW, the sum of which is $15.9 \%$ of the generation of MSW. Meanwhile,

3120.280 million tonnes of incineration residue which is generated from the incineration of foreign

313 objects at sorting facilities and recycling facilities is included in the amount of incineration residue.

314 In this study, through the analysis on the material flow, the amounts of incineration and landfill

315 were calculated including first generated MSW as well as foreign objects and incineration residue

316 generated from the processes of its sorting, recycling and treatment. Consequently, the sum of

317 treated amounts is larger than the amount of MSW generated first. While the incineration rate in

318 'Nationwide Status of Waste Generation and Treatment in 2016' was 25.3\% and the landfill rate

$31914.7 \%$ [9], where incineration rate and landfill rate are calculated based only on the direct input

320 amount to incineration facilities and landfill facilities after the collection of MSW. However, actual

321 incineration rate and final disposal rate are higher than these by $7.5 \%$ and $8.4 \%$ respectively.

322

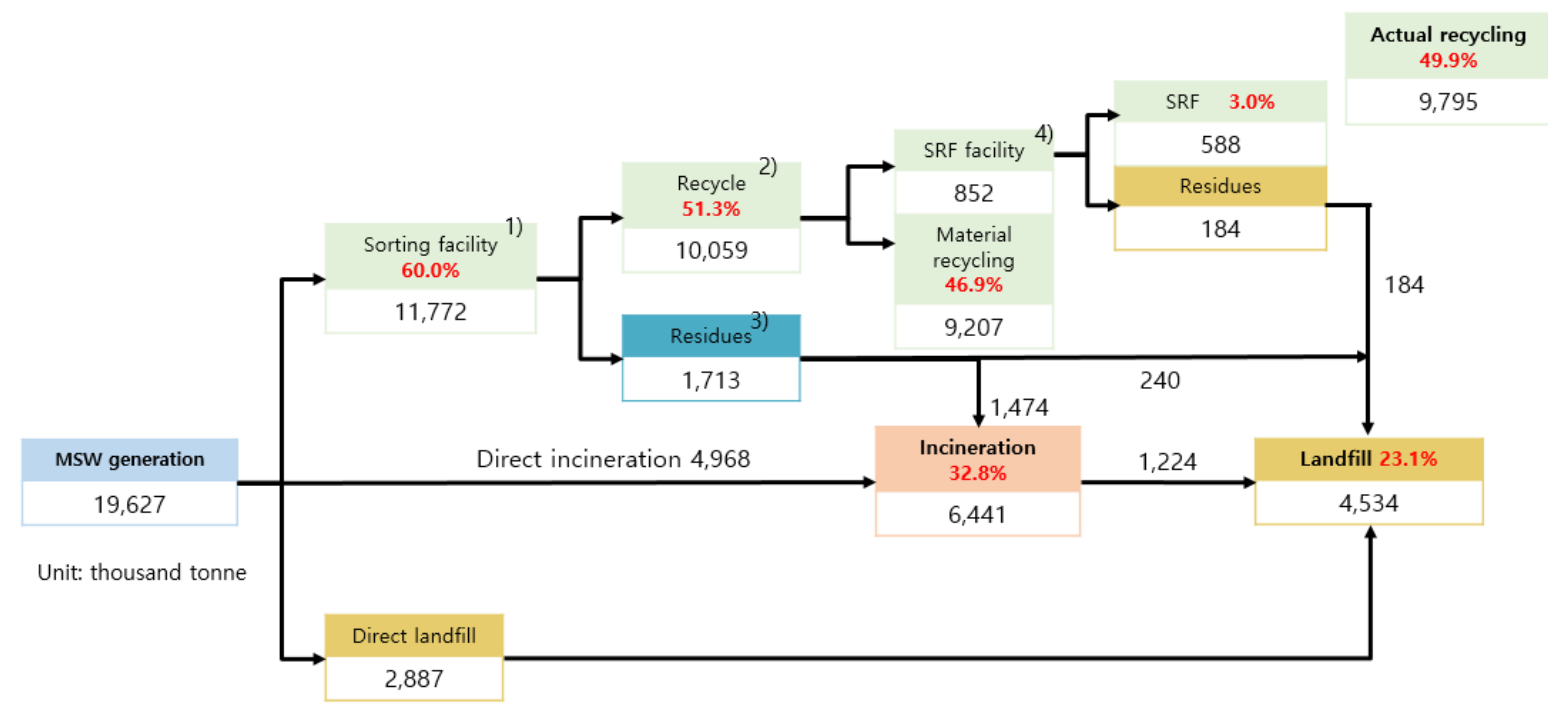

324 Figure 2. Simplified Material flow of MSW treatment (2016).

325 Note) Because the numbers are rounded, the totals may not match, and percent values in 326 parentheses are the ratios to the generation of MSW.

327 1) The value is the sum of recyclable resources input to sorting facility, food waste recycling 
328 facility, recovered resource at a storage and transshipment facility, and SRF facility from

329 designated plastic bag waste (general MSW which is managed by volume-based fee).

330 2) The value is the sum of sorted resources, food waste except residues, recovered resource at a 331 storage and transshipment facility, and SRF facility from wastes in designated plastic bag (general 332 MSW which is managed by volume-based treatment fee).

333 3) The value is the sum of residues from sorting facility and food waste recycling facility.

334 4) The value is the sum of EPR target plastic sheet, and input to SRF facility from wastes in 335 designated plastic bag.

336

\subsubsection{Change in material flow resulting from the change in treatment methods for MSW}

340 disposal rates of MSW, it is necessary to change the waste treatment method of a direct landfill with 341 designated plastic bag to the SRF manufacturing or the incineration of food wastes. The following 342 shows the results of MFA for the case of changing treatment methods in such a way.

1) When SRF is manufactured from the directly landfilled wastes in designated plastic bag

344 The MFA results when fluff SRF is manufactured from the directly landfilled wastes in designated 345 plastic bag are shown in Figure 3. As described in Section 3.2.1, material balance for SRF 346 manufacturing process was calculated by assuming $54.9 \%$ for production yield, $30.7 \%$ for generation 347 rate of foreign objects, and $14.4 \%$ for process loss rate. When 2.837 million tonnes of wastes in 348 designated plastic bag are input to SRF manufacturing facilities as shown in Figure 3, 1.558 million 349 tonnes of SRF is produced along with 0.871 million tonnes of foreign objects, and the amount of 350 process loss is 0.409 million tonnes. When compared with 2016 treatment results for MSW (Figure 2), 
351 the actual recycling rate was increased from $49.9 \%$ to $57.8 \%$ by $7.9 \%$, while the actual final disposal

352 rate is decreased from $23.1 \%$ to $13.1 \%$ by $10.0 \%$. Assuming that SRF was substituted for fossil

353 fuels, the treatment of combustion residue generated after combustion was not considered.

354 However, the amount of combustion residue was 0.296 million tonnes corresponding to $1.5 \%$ of 355 the generation of MSW if the amount of combustion residue would be assumed to be the same as 356 the generation ratio of incinerated materials $(19 \%)$.

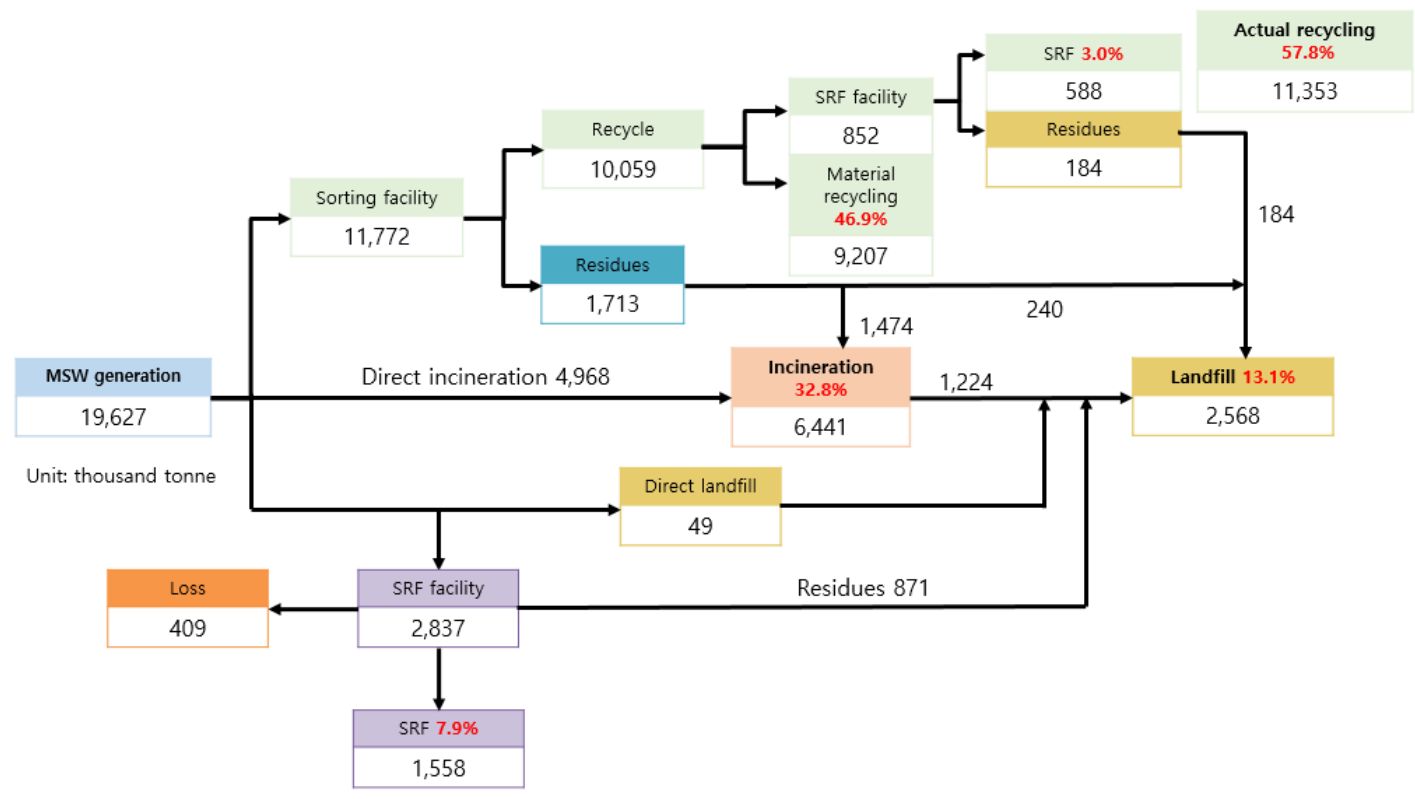

359 Figure 3. Material flow of directly landfilled wastes in designated plastic bags to be used for SRF 360 manufacturing.

361 Note) The values and percentages are the same as the notes and footnotes of the Figure 2.

2) When directly landfilled wastes are treated by incineration

364 When the entire amount of directly landfilled wastes in designated plastic bag and food wastes 365 among MSW was treated for incineration, material flow was calculated and shown in Figure 4 . When 366 treated in such a way, the amount of incineration was 9.328 million tonnes corresponding to $47.5 \%$ 
367 compared with the generation amount, while the amount of final disposal was 2.196 million tonnes

368 corresponding to $11.2 \%$ compared with the generation amount. When compared with 2016 treatment

369 results for MSW (Figure 2), the incineration rate was increased from $32.8 \%$ to $47.5 \%$ by $14.7 \%$,

370 while the final disposal rate was decreased from $23.1 \%$ to $11.2 \%$ by $11.9 \%$.

371

372

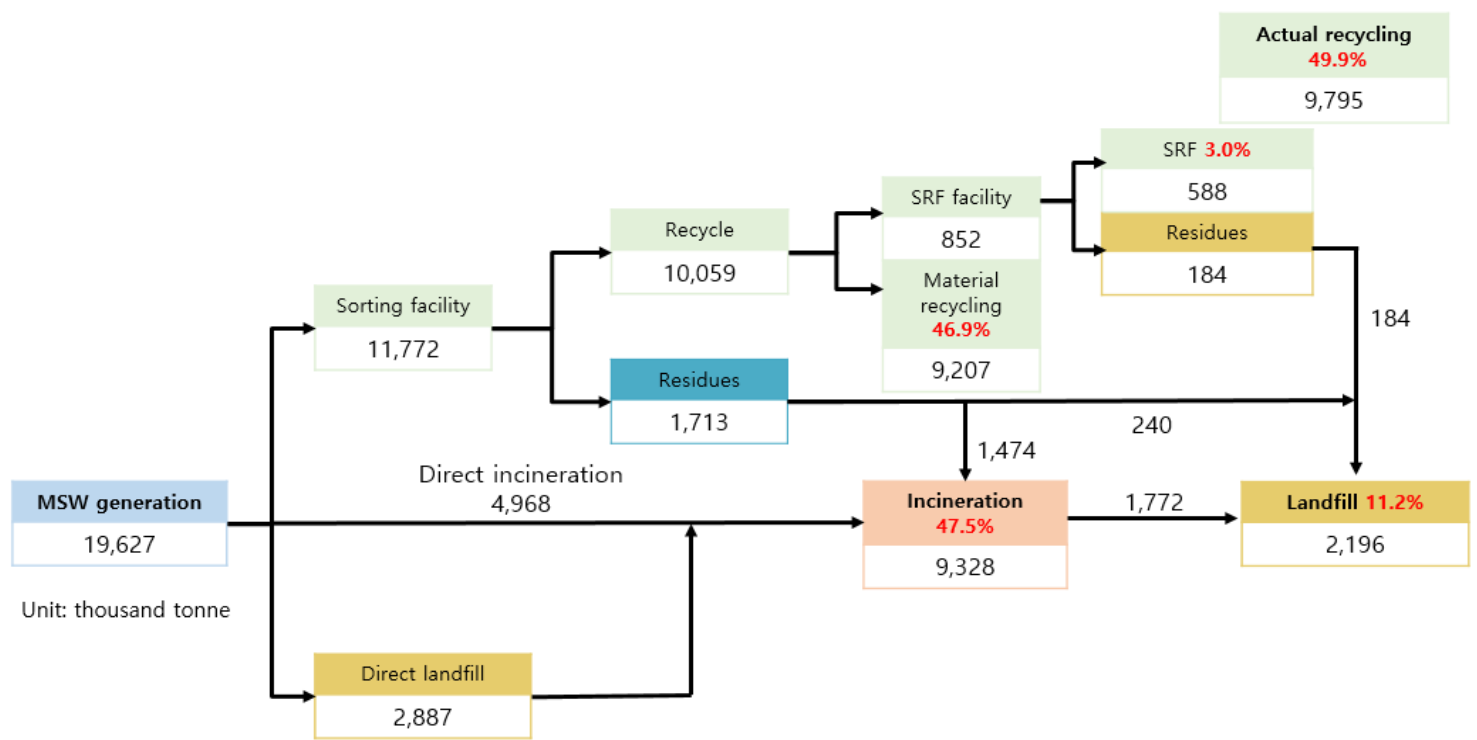

373 Figure 4. Material flow of directly landfilled wastes in designated plastic bags to be incinerated.

374 Note) The values and percentages are the same as the notes and footnotes of the Figure 2.

3.2.4. Change in the ratios per treatment method resulting from the change in the treatment method

377 for $M S W$

378 Based on 2016 treatment status of MSW described above, material flows were analyzed for the 379 cases where the treatment method for the originally landfilled wastes in designated plastic bag was 380 changed to the manufacturing of SRF and where all of directly landfilled wastes in designated 381 plastic bag and food wastes were changed to the incineration. The amounts of recycling, 382 incineration, and final disposal were obtained, and the ratios accounted for the generation of MSW 
383 by these amounts of treatment have been arranged and shown in Table 1.

384 As indicated in Table 1, the manufacturing of SRF from directly landfilled wastes in designated 385 plastic bag is advantageous to increase the recycling rate, while the incineration of directly 386 landfilled wastes is advantageous to reduce the final disposal rate. However, some incineration 387 facilities produce electricity or/and steam by recovering incineration heat and use them as 388 alternative energy. Such incineration facilities tend to increase gradually. However, the recovery 389 and use of incineration energy have not been considered in this study. Also, as described in Section 3902.3 , neither the amount of combustion residues generated from the use of SRF has been included 391 in the landfill amount.

392 As a reference, 2016 final disposal rate of MSW in Japan was 9.7\%. It was lower than the final 393 disposal rate in Korea with $11.2 \%$ by $1.5 \%$ which was calculated under the condition of all of the 394 land-filled wastes being treated for incineration. However, the final disposal rate is lowered to $3959.5 \%$ if 0.423 million tonnes of landfill amount (2.2\% of the MSW generation) among foreign 396 objects generated in the recycling process of MSW being treated by incineration, and the 397 generation rate of incineration residue is assumed to be $19 \%$.

398

399 Table 1. Comparison of treatment amount and its ratio of each treatment method (Unit: thousand 400 tonne).

\begin{tabular}{cccccc}
\hline \multirow{2}{*}{ Treatment condition } & & Total & Recycle & Incineration & Landfill \\
\hline Treatment status & & & & & \\
in 2016 & Weight & 19,627 & 9,795 & 6,441 & 4,534 \\
\cline { 2 - 6 } & Ratio (\%) & - & 49.9 & 32.8 & 23.1 \\
\hline SRF manufacturing by designated & Weight & 19,627 & 11,353 & 6,441 & 2,568 \\
\cline { 2 - 6 } plastic bag waste & Ratio (\%) & - & 57.8 & 32.8 & 13.1 \\
\hline
\end{tabular}




\begin{tabular}{lccccc}
\hline \multirow{2}{*}{ Incinerating all direct landfill waste } & Weight & 19,627 & 9,795 & 9,328 & 2,195 \\
\cline { 2 - 6 } & Ratio (\%) & - & 49.9 & 47.5 & 11.2 \\
\hline
\end{tabular}

401

402

403

404

405

406

407

408

409

410

411

412

413

414

415

416

417

418

419

420

421

422

\subsection{Calculation and comparison of waste disposal charge according to the change in treatment} methods for MSW

Based on the Framework Act on Resource Circulation in Korea, the waste disposal charge system has been enforced since 2018. The criteria for reduction and calculation of the charge are specified in Annex 5 and Annex 6 of the enforcement decree for the same Act. Among these, the criteria for reduction and calculation related to MSW are as shown in Table 2 and Table 3 respectively. The Article 7 of the Enforcement Decree of the Korean Waste Management Act stipulates that wastes generated from the process of recycling and intermediate treatment should be regarded as newly discharged wastes. As a result, the sorting residual waste and incineration ash from the MSW treatment are managed as industrial wastes.

Since the foreign objects generated in sorting facilities for recyclable resources and manufacturing facilities for SRF generally have combustible contents with more than 5\% based on weight, the rate for combustible waste was applied among industrial and commercial wastes, while the rate for non-combustible material among industrial and commercial wastes was applied to the incineration residue because its combustible contents is judged to be less than $5 \%$ based on weight. In accordance with the related regulations of enactment decree for the same act, the rates of contribution to waste disposal per $1 \mathrm{~kg}$ of MSW as shown in Table 3 are 15 Korean won (KRW) for direct landfill treatment and $10 \mathrm{KRW}$ for incineration, while that for landfill of foreign objects is $25 \mathrm{KRW}, 10 \mathrm{KRW}$ for incineration, and $10 \mathrm{KRW}$ for the landfill of incineration residue. Meanwhile, the reduction rates in case of incineration for MSW and foreign objects are as shown in Table 2. 
423 Table 2. Reduction conditions and rates of waste treatment charge.

\begin{tabular}{cc}
\hline Recovery and utilization rate of incineration heat energy (\%) & Reduction rate (\%) \\
\hline $75 \sim$ & 75 \\
\hline $60 \sim 75$ & 60 \\
\hline $50 \sim 60$ & 50 \\
\hline
\end{tabular}

425 Table 3. Waste treatment charges by waste type and treatment method.

\begin{tabular}{|c|c|c|c|}
\hline \multirow{2}{*}{ Waste type } & & \multicolumn{2}{|c|}{ Waste treatment method } \\
\hline & & Landfill $\left(\mathrm{KRW} \cdot \mathrm{kg}^{-1}\right)$ & Incineration $\left(K R W \cdot \mathrm{kg}^{-1}\right)$ \\
\hline MSW & & 15 & 10 \\
\hline \multirow{2}{*}{$\begin{array}{l}\text { Industrial \& commercial waste } \\
\text { (except construction and } \\
\text { demolition waste) }\end{array}$} & Non-combustible & 10 & - \\
\hline & Combustible & 25 & 10 \\
\hline
\end{tabular}

426

The change in treatment amounts per treatment method according to the treatment conditions

428 for MSW and the waste disposal charge have been calculated and shown in Table 4. As seen from

429 Table 4, the charge amount is the highest with 130,533 million KRW for 2016 treatment condition

430 (Type 1), and with 121,584 million KRW if the direct landfill wastes are incinerated in the

431 incineration facilities with a recovery and use rate for incineration thermal energy of lower than

$43250 \%$ (Type 3A), with 109,749 million KRW if SRF is manufactured from designated plastic bag

433 wastes (Type 2), with 74,944 million KRW if the direct landfill wastes are incinerated in the

434 incineration facilities with a recovery and use rate for incineration thermal energy of higher than

$43550 \%$ and lower than $60 \%$ (Type 3B), with 65,616 million KRW if the direct landfill wastes are

436 incinerated in the incineration facilities with a recovery and use rate for incineration thermal energy 
437 of higher than $60 \%$ and lower than 75\% (Type 3C), and with 51,624 million KRW if the direct

438 landfill wastes are incinerated in the incineration facilities with a recovery and use rate for 439 incineration thermal energy of higher than 75\% (Type 3D). When SRF is manufactured from 440 landfilled wastes in designated plastic bag, compared with 2016 treatment condition for MSW, the 441 charge amount is reduced by 20,784 million KRW, while the amount is reduced by 78,909 million 442 KRW if the direct landfill wastes are incinerated in the incineration facilities with a recovery and 443 use rate for incineration thermal energy of higher than $75 \%$.

445 Table 4. Waste treatment charges and amounts by treatment methods according to treatment 446 conditions.

\begin{tabular}{|c|c|c|c|c|c|c|}
\hline \multirow{2}{*}{\multicolumn{2}{|c|}{ Waste treatment condition }} & \multirow{3}{*}{$\begin{array}{c}\text { Total } \\
-\end{array}$} & \multirow{3}{*}{$\begin{array}{c}\text { Incineration } \\
6,441\end{array}$} & \multicolumn{3}{|c|}{ Landfill } \\
\hline & & & & \multirow{2}{*}{$\begin{array}{c}\text { Direct landfill } \\
2,887\end{array}$} & \multirow{2}{*}{$\begin{array}{c}\text { Residues } \\
423\end{array}$} & \multirow{2}{*}{$\begin{array}{c}\text { Ash } \\
1,224\end{array}$} \\
\hline \multirow{2}{*}{ Type 1} & Waste (thousand tonne) & & & & & \\
\hline & Charge (one million KRW) & 130,533 & 64,412 & 43,303 & 10,580 & 12,238 \\
\hline \multirow{2}{*}{ Type 2} & Waste (thousand tonne) & - & 6,441 & 49 & 1,294 & 1,224 \\
\hline & Charge (one million KRW) & 109,749 & 64,412 & 742 & 32,357 & 12,238 \\
\hline \multirow{2}{*}{ Type 3A } & Waste (thousand tonne) & - & 9,328 & 0 & 423 & 1,772 \\
\hline & Charge (one million KRW) & 121,584 & 93,280 & 0 & 10,580 & 17,723 \\
\hline Type 3B & Charge (one million KRW) & 74,944 & 46,640 & 0 & 10,580 & 17,723 \\
\hline Type 3C & Charge (one million KRW) & 65,616 & 37,312 & 0 & 10,580 & 17,723 \\
\hline Type 3D & Charge (one million KRW) & 51,624 & 23,320 & 0 & 10,580 & 17,723 \\
\hline
\end{tabular}

447 Note 1) Type 1: Waste treatment condition of MSW in 2016, Type 2: Conversion of treatment 448 method of direct landfilled waste which is discharged by designated plastic bag, to SRF production, 449 Type 3A: Conversion of treatment method of all directly landfilled wastes to incineration 450 (incineration heat energy recovery and utilization rate is less than 50\%), Type 3B: Same condition 
451 with Type $3 \mathrm{~A}$ but incineration heat energy recovery and utilization rate is increased from $50 \%$ to $45260 \%$, Type 3C: Same condition with Type 3A but incineration heat energy recovery and utilization 453 rate is increased from $60 \%$ to $75 \%$, Type 3D: Same condition with Type $3 \mathrm{~A}$ but incineration heat 454 energy recovery and utilization rate is increased to $75 \%$ and more.

455 Note 2) The waste treatment charge was expressed in the unit of one million KRW and the sum 456 may not be matched due to rounding of numbers. in 2016 was analyzed and the following results have been obtained.

1. From the MFA for the conditions of treatment according to 2016 treatment status for MSW, actual recycling rate, incineration rate, final disposal rate compared with MSW generation were obtained as $49.9 \%, 32.8 \%$, and $23.1 \%$, respectively, which are lower by $10.1 \%$ than the recycling rate of $60.0 \%$, the incineration rate of $25.3 \%$, and the final disposal rate of $14.7 \%$ in the 'Nationwide Status of Waste Generation and Treatment in 2016', and the incineration rate and final disposal rate were higher by $7.5 \%$ and $8.4 \%$ respectively. plastic bag in 2016, then 1.558 million tonnes of SRF is produced, while the actual recycling rate, incineration rate and final disposal rate become $57.8 \%, 32.8 \%$, and $13.1 \%$ respectively, so that the 470 actual recycling rate becomes higher than the original rate by $7.9 \%$ and the actual final disposal 471 rate is lower by $10.0 \%$.

$472 \quad 3$. If all 2.887 million of the directly landfilled wastes in designated plastic bag and food wastes 473 in 2016 are treated for incineration, then the actual recycling rate, incineration rate, and final 
474 disposal rate become $49.9 \%, 47.5 \%, \& 11.2 \%$ respectively, so that the actual incineration rate

475 becomes higher than the original rate by $14.7 \%$ while the actual final disposal rate is lower by $476 \quad 11.9 \%$.

477 4. According to the calculation result for the total waste disposal charge to waste treatment of 478 MSW generated in 2016, it is 130,533 million KRW if it is treated according to the treatment 479 method of 2016, and it is reduced to 109,749 million KRW if SRF is manufactured from directly 480 landfilled wastes in designated plastic bag. If all directly landfilled wastes in designated plastic 481 bag and food wastes are incinerated, then it is reduced to 121,584 million KRW, 74,944 million $482 \mathrm{KRW}, 65,616$ million KRW, and 51,624 million KRW when the energy recovery and use rates of 483 the incineration facility are less than $50 \%$, more than $50 \%$ and less than $60 \%$, more than $60 \%$ and 484 less than $75 \%$, and more than $75 \%$ respectively.

485 In this study, actual recycling rate, incineration rate, \& final disposal rate were calculated 486 through the MFA from generation to treatment of MSW in South Korea. However, since official 487 data for the calculation of material balance for treatment processes of wastes was insufficient, the 488 data of Statistics Korea, evaluation results data on the installation and operation status of public 489 MSW treatment facilities of Korea Environment Corporation, the internal data of related 490 institutions, etc. were utilized based on MSW generation of nationwide status for the generation $491 \&$ treatment of wastes in 2016 so that there exists some limitation in terms of the accuracy. The 492 establishment of the realistic resource circulation policies and the accomplishment of the exact 493 outcome evaluation should be based on the results of MFA for the entire process from the 494 generation of wastes to the final treatment. It is expected that this study will be usefully utilized in 495 the future for the establishment of resource circulation policies and the MFA on MSW. 
497

498

499

500

501

502

503

504

505

506

507

508

509

510

511

512

513

514

515

516

517

518

519

\section{Appendix. Supplementary materials}

The following are the Supplementary data to this article:

\section{Acknowledgement}

This work was supported by a grant from the National Institute of Environmental Research (NIER), funded by the Ministry of Environment (MOE) of the Republic of Korea (NIER-201801-01-041).

Conflicts of Interest: The authors declare no conflict of interest.

\section{References}

1. Ministry of Environment of Korea, 2017a. National waste generation and treatment in 2016, pp. 57 (Ver. Korean).

2. Ministry of Environment of Korea, 2017b. National waste generation and treatment in 2016, pp. 101 (Ver. Korean).

3. Korea Statistical Office, Housing Census (Resident by house type, date of date update August $31^{\text {st }}, \quad 2017, \quad$ duration of $\quad$ recording 2016). http://kosis.kr/statHtml/statHtml.do?orgId=101\&tblId=DT_1JC1505\&vw_cd=MT_ZTIT LE\&list_id=A12_2015_1_10_10\&seqNo=\&lang_mode $=$ ko\&language $=$ kor\&obj_var_id $=\& i t m \_i d=\&$ conn_path=MT_ZTITLE (accessed 1 August 2018).

4. Korea Resource Circulation Service Agency, 2017. Amount received and recycled by recycling company for each EPR item in 2016 (internal data).

5. Korea Environment Corporation, 2017a. Evaluation of operation status of public 

municipal solid wastes treatment facilities in 2016 (internal data).

6. Korea Environment Corporation, 2017b. SRF (solid refuse fuel) production by waste plastic film of EPR item in statistics of SRF in 2016 (internal data).

7. Ministry of Environment of Korea, 2018. Evaluation of operation status of separate food waste recycling in 2016 (internal data).

8. Korea Environment Corporation, 2017c. SRF (solid refuse fuel) production by MSW discharged by a designated plastic bag statistics of SRF in 2016 (internal data).

9. Ministry of Environment of Korea, 2017c. National waste generation and treatment in 2016, pp. 25 (Ver. Korean).

\section{Appendix}

An Estimation of Actual Recycling and Final Disposal Rates of Municipal Solid Waste by

Material Flow Analysis in Korea

\section{Jung-Keun Oh ${ }^{1}$, Ji-Yeon Kim ${ }^{1}$, Yoon-A Cho ${ }^{1}$, Ki-Heon Kim ${ }^{1}$, Gil-Jong Oh ${ }^{1, *}$}

${ }^{1}$ Environmental Resources Research Department, National Institute of Environmental Research, Hwangyeong-ro 42, Seo-gu, Incheon 404-708, Republic of Korea

\section{Content}

Appendix A - Material flow of MSW treatment in Japan and Germany

$$
\text { Appendix B - The generation and treatment status of MSW in Korea, } 2016
$$


544

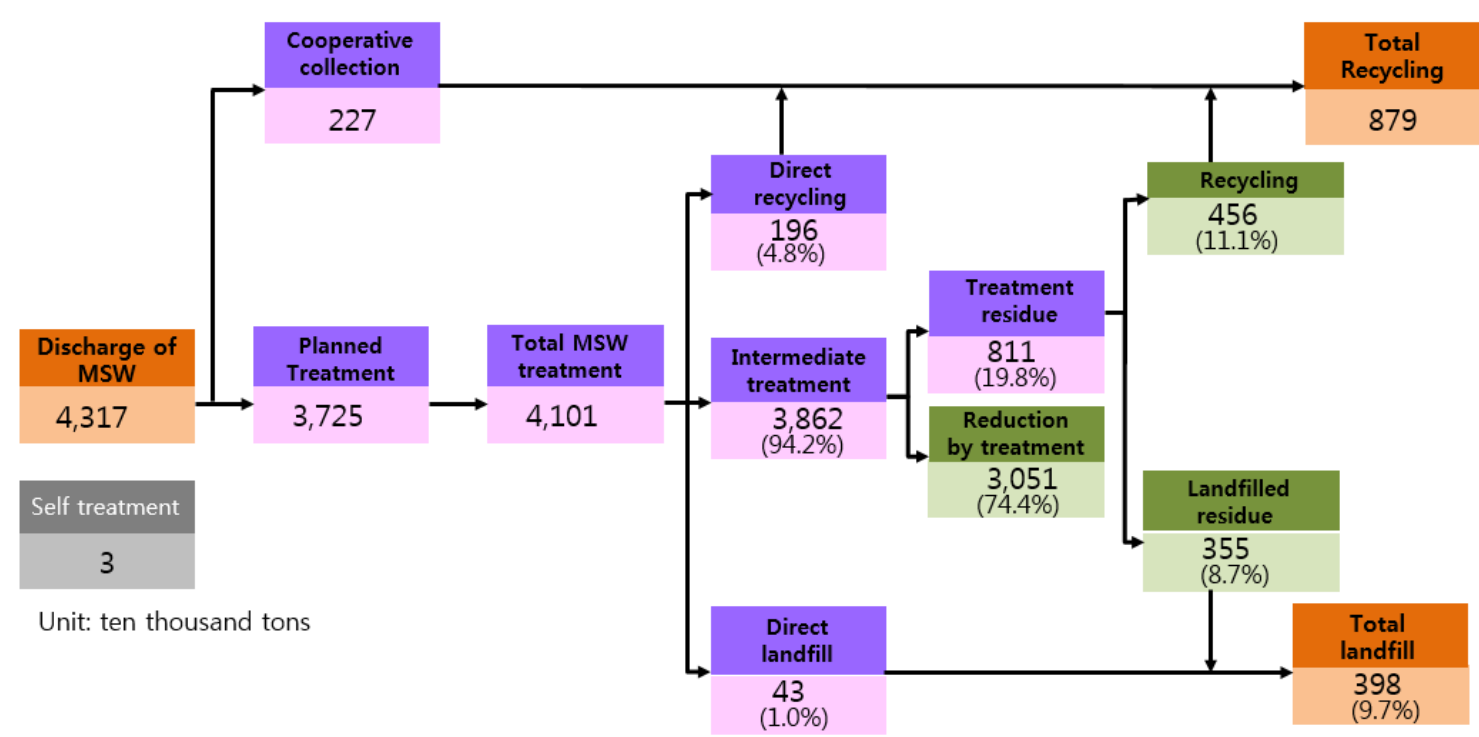

545 Figure A1. Material flow of MSW treatment in Japan (Ministry of the Environment of Japan, 2018)

546 1) The numbers in parentheses are percentages of total amount of treated waste. 2) Planned

547 treatment amount of waste and total amount of treat waste (sum of waste amount which is treated

548 by intermediate treatment, final disposal, and direct recycling) do not match due to difference

549 between planned treatment amount and actual treated amount. 3) Direct recycling is the amount

550 supplied directly to recycling companies without sorting or intermediate treatment. 


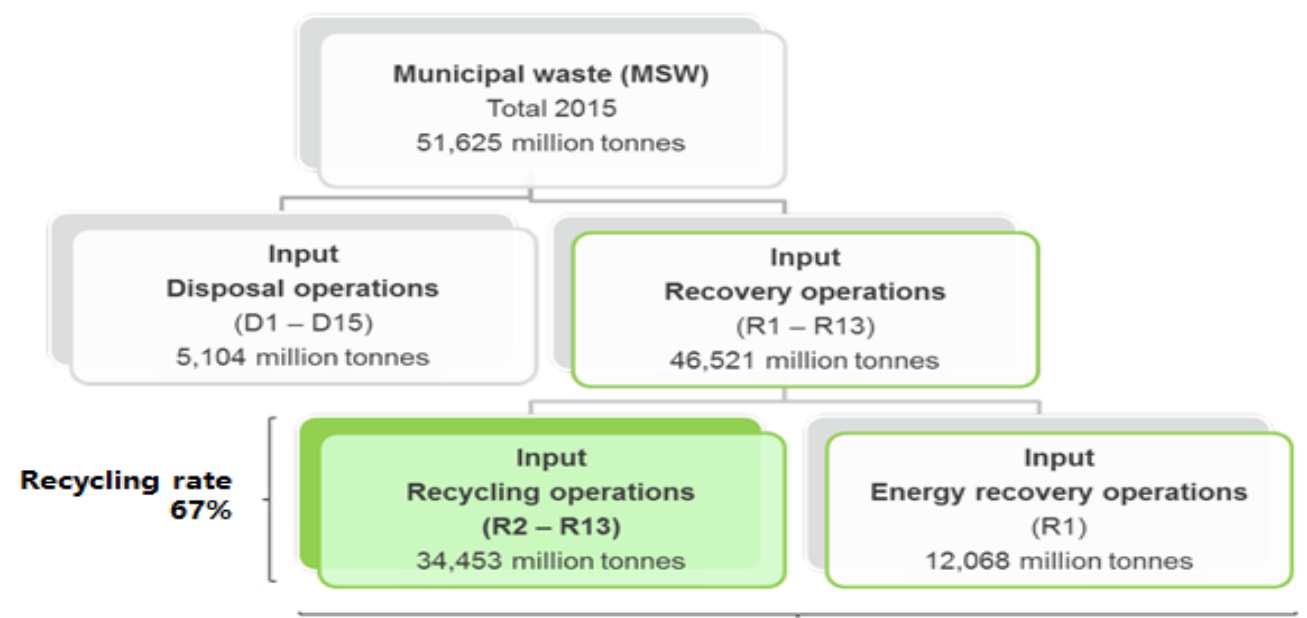

Recovery rate $90 \%$

552 Figure A2. Material flow of MSW treatment in Germany. (Thomas and Sylvia, 2017)

553

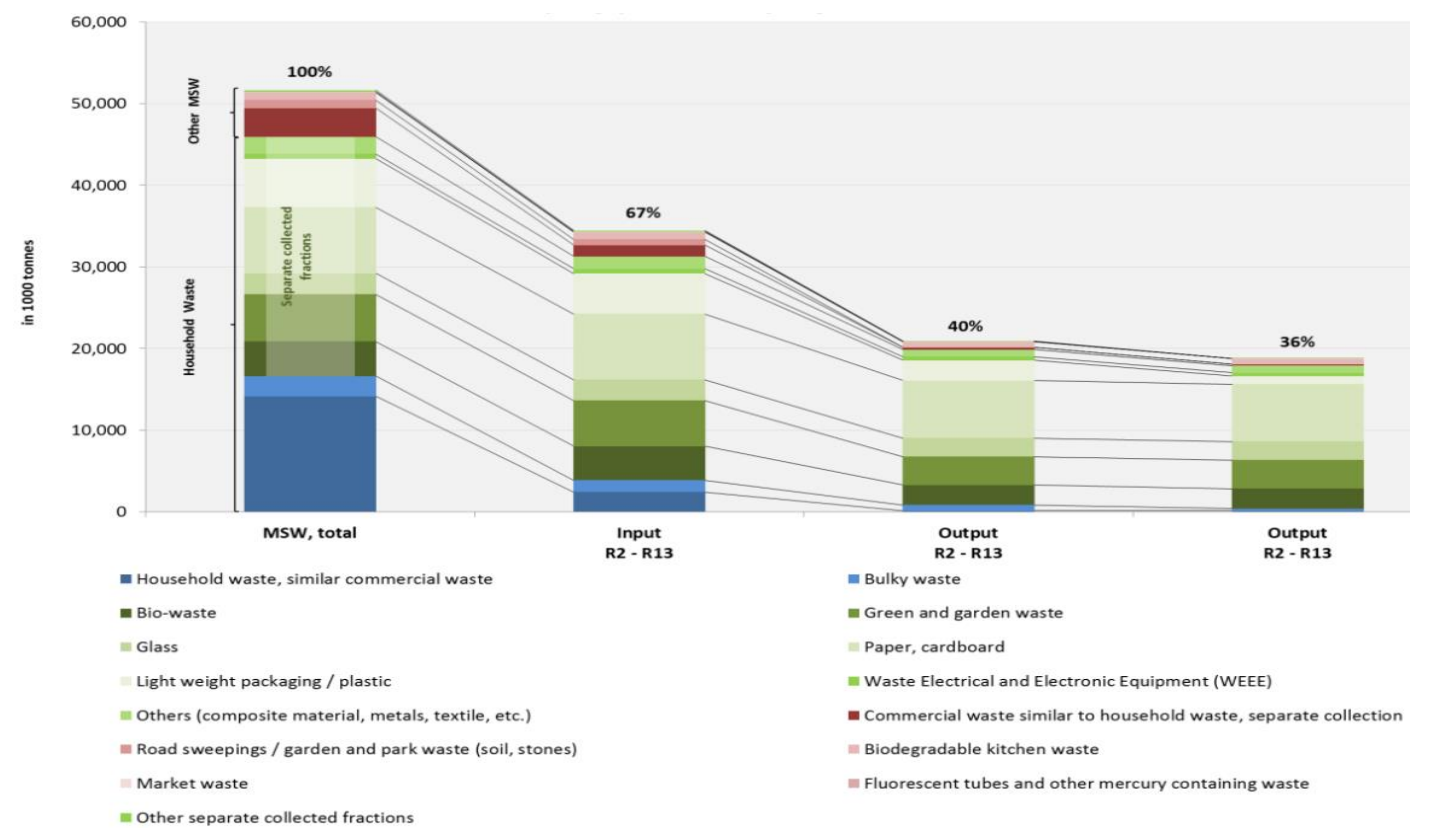

554 Figure A3. Change of recycling rate according to the recycling stage in Germany. (Thomas and 555 Sylvia, 2017)

556

557 Appendix B. The generation and treatment status of MSW in Korea, 2016

558 Table B1. The generation and treatment status of MSW in 2016 (Ministry of the Environment of 559 Korea, 2017c) 


\begin{tabular}{|c|c|c|c|c|}
\hline Classification & Total & $\begin{array}{c}\text { Waste in designated } \\
\text { plastic bag }\end{array}$ & $\begin{array}{l}\text { Recyclable } \\
\text { resources }\end{array}$ & Food waste \\
\hline Total waste (tonne·day ${ }^{-1}$ ) & $53,771.9(100 \%)$ & $24,965.5$ & $14,417.7$ & $14,388.7$ \\
\hline Landfill (tonne $\cdot$ day $^{-1}$ ) & $7909.2(14.7 \%)$ & $7,773.7$ & 0.0 & 135.5 \\
\hline Incineration (tonne $\cdot$ day $^{-1}$ ) & $13,609.8(25.3 \%)$ & $13,292.9$ & 0.0 & 316.9 \\
\hline Recycle (tonne $\cdot$ day $^{-1}$ ) & $32,252.9(60.0 \%)$ & $3,898.9$ & $14,417.7$ & 13.936 .3 \\
\hline
\end{tabular}

560

$561 \quad$ References

562 Ministry of the Environment of Japan, 2018. Environmental White Paper, pp. 161.

563 Thomas, O., Sylvia, L., 2017. New Calculation Method for Measurement of Recycling Rates and

564 Influence on Recycling Quotas, Last Changed on 20 July 2017, pp. 5-9.

565 Ministry of Environment of Korea, 2017c. National waste generation and treatment in 2016, pp.

56625 (Ver. Korean). 